\title{
Female Genital Mutilation: Types, Consequences and Constraints of Its Eradication in Nigeria
}

\author{
${ }^{1}$ Dr. G.O. Ayenigbara, ${ }^{2}$ S.I. Aina and ${ }^{3}$ T.D. Famakin \\ ${ }^{1,2,3}$ Human Kinetics And Health Education Department, Adekunle Ajasin University, Akungba - Akoko, \\ Ondo State.
}

\begin{abstract}
Female Genital Mutilation (FGM) also known as female circumcision is a practice which is entrenched in African culture. Archaic as this practice is, it is widely carried out in Nigeria with its attendant deleterious effects. Various methods of female genital mutilation practice in Nigeria include circumcision, infibulations, intermediate infibulations, excision and the unclassified method. Among the health problems associated with FGM are shock, hermorrage, infections, vesico vaginal fistula and trauma. Efforts to eradicate female genital mutilation in Nigeria are hampered by ignorance, economic motives culture, tradition, male prejudice and non- challant attitude of the Federal Government. Nevertheless, this practice must be stopped through education of the public and legislation by the Federal Government among other measures.
\end{abstract}

Key Words

1. Female Genital Mutilation

2. hemorrhage

3. Excision

4. Infibulation

5. Circumcision

\section{Introduction}

Female Genital Mutilation (FGM) is about a 2,500 year - old tradition still being practiced in several countries, but it is most prevalent in the African Continent (Anderson, 1992). Infact some authors see the practice as a component part of the African Culture (Anderson, 1992 and Black 1993). Female Genital Mutilation is any form of distortion of the external genitalia using any form of traditional or modern instrument. Female Genital Mutilation, also commonly known as female Circumcision (FC), is a practice which involves the cutting off part or whole of a girls clitoris and some other parts of her sex organs whether for cultural, religious or any other non - therapeutic reasons (WHO 1995).

Female Genital Mutilation has been discovered to be a serious harmful traditional practice. It can be described as a cause of serious health hazard for the girl child or woman, inflicting pain, trauma and body injuries (Mutilation). It offers no benefit to anyone other than a misplaced sense of satisfaction. FGM could be carried out in infancy early childhood, at puberty, shortly before marriage, during first pregnancy and even on the uncircumcised dead woman, regrettably under circumstances that does not take into consideration sepsis, pain, bleeding, trauma and other psychological and physiological implications or knowledge of the female external genitalia (Durkenoo 1994)

WHO (1995) identified four types of FGM currently practiced world wide. These include excision or reduction of the prepuce with or without excision of part or all of clitoris (clitoridectomy). The second type is the excision of the clitoris and the prepuce while the third type is the excision of part or all of the eternal genitalia and stitching or narrowing of the vaginal opening (infibulations). This type is sometimes called Pharaonic or Sudanese circumcision. The fourth type is termed unclassified, it includes clitoral pricking, piercing or incision, stretching, cauterization, scraping and others that fall under FGM definition.

Clitoridectomy is preferred to any other types and is widely practiced in many parts of the world (Hosken 1993). Pharaonic circumcision is the most extreme, most severe and most devastating of all the forms of genital mutilation in existence. It is believed to have been practiced in Upper Egypt during the reign of Pharaoh (Anderson 1990)

Women are the victims of this outdated custom and male prejudice. Even though there are other forms of sexual subjugation, but this particular one is based on the manipulation of women's sexuality in order to assume male dominance and exploitation. The origin of such practice may be found in the family, society or religion (Alan 1994). This obnoxious practice of FGM has been ignorantly justified and given many reasons, which include the prevention of immortality; preparing females for marriage; to ensure cleanliness; to prevent labia hypertrophy; to improve fertility to give more pleasure to the husband (by tightening the vagina), for religious rights and obligation (Hosken, 1993). These justifications for the motives and functions of FGN are at first glance bewildering, often conflicting and always at odds with biological facts $\mathrm{f}$ (Efua, 1993). 
The age at which females are circumcised in different societies varies. In Burkina - Faso and CoteD'voire, it is carried out at the age between 10 and 12 years. In Nigeria, the age varies from one ethnic to another. It is performed in some communities during infancy, in the first eight years or two weeks of life, as is the case among people of Ese-Odo Local Governments Area of Ondo State, and among Owu people in Abeokuta, Ogun State, Ibadan in Oyo state, the Igbo in the East, and among Muslims in some parts of the North (Adeneye, 1995 Onadeko, et al 1985; Ezumezu, 1993). Female genital mutilation is performed at a much later stage in life of girls and women (i.e between 13 and 18 years) in Okpe community in Delta State and among the Ibiobio in Akwa Ibom State (Owumi, 1993 and Akpabio 1995). Further more, females are circumcised during pregnancy and just before they deliver their babies.

\section{Types of Female Genital Mutilation practiced in Nigeria.}

Nigeria is the most populous country in Africa with majority of the people living in the rural areas where poverty, ignorance superstition, lack of basic infrastructure (good roads, portable water, electricity, health care services etc). diverse cultural beleiefs and tradition are the predominant features, so different types of FGM are practiced. The main types are:

1. Circumcision:- This is the removal of the prepuce or hood of the clitoris. This is the mildest type of mutilation and it is carried out on a small proportion of millions in Nigeria.

2. Infibulations:- This method involves the cutting of the third, often the whole of the medial part of the labia majora. The two sides of the vulva are then pinned together by silk or thorns thus obliterating the vagina introitus except for the small opening preserved by the insertion of tiny pieces of wood or reed for the passage of urine and menstrual blood (Assaud 1990). The girls legs are then bound together from hip to ankle, and she is kept immobile up to forty days to permit the formation of damaged tissues. In some communities, there is no stitching, but to facilitate healing, the raw edge of the wound are brought together by adhesive substance such as eggs, sugar or acacia tar, and the girl is kept immobile. In rare case, animal excreta are placed on the wound as observed among people in Western Sudan (Assaud, 1990).

3. Intermediate Infibulations:- This method entails different forms of mutilation followed by variable degrees of stitching. In one type the clitoris is removed and the surface of the labia minora roughened to allow stitching (Dareer, 1993). In other types, the clitoris is left intact but the labia minora are removed. The insides of the labia majora are removed and stitched with the clitoris buried underneath.

4. Excision:- This is the partial or total cutting of the clitoris and all or part of the labia minora. In some cases, the labia majora are removed but with no stitching. Excision is the most common types of mutilation. Approximately $80 \%$ of those affected undergo excision (Gudeta 1994)

5. Unclassified Methods:- These include scarification of the clitoral prepuce, cuts into the clitoris and labia minora as well as into the vagina, for example the "gishiri" cut as practiced in parts of Northern Nigeria.

\section{Consequences of Female Genital Mutilation:-}

The practice of FGM exposes victims to serious infections and other health hazards which include HIV/AIDS, tetanus, hepatitis B and haemorrhge (Insel and Roth, 2006). The practice is dehumanizing, the consent of the victims were neither sought nor received, and they were often subjected to untold agonies.

Various types of unsterilized instruments used for the operation range from special knives, scissors, scalpels, pieces of glass, razor blades, finger nails and herb mictures. Cowdung, chickens or dog feaces, earthen or ashes which are thought to contain some clotting properties are rubbed on the wound to stop bleeding (The Minority Right Group report (1985). All these instruments and materials initiate, complicate and aggravate post - operation infections.

In addition, female genital mutilation may cause phobia (fear) of sexual intercourse. For instance, failure or incomplete healing of wounds on the Vagina makes penetration by the sexual partner painful for the female. Additional injury may be sustained on the sex organs during sexual intercourse, especially, if the male partner is aggressive in his approach. This condition may cause frigidity on the part of the woman, and this lack of interest in love making may lead to matrimonial conflicts and even divorce. (Insel and Rath, 2006).

Female genital mutilation is one of the most serious forms of human degradation and violence against women. It symbolizes the subjugation of women and the control of female sexuality. Since it is mostly carried out at a very young age, when there is no possibility of having the victims consent, it is a fundamental violation of human right. Infibulations may lead to the re-opening of passages between the vagina and bladder or anus, producing Vesico-Vagina Fistula (VVF) or Rectum-Vagina Fistula (RVF), conditions more commonly associated with the result of obstructed labour in early pregnancy but arising also, in some cases, from cutting open of infibulated women. The continual leakage of urine and or feaces by VVF / RVF victims result in their being rejected by their husbands and other members of the society. The incidence of VVF is estimated at 2 per 1000 deliveries (Sambo 1993), and the harmful traditional practices study has reported that $80-90 \%$ of wives with VVF are divorced by their husbands (UNDS 1998) 
Strained marital relationship can develop as a consequence of FGM. Painful sexual intercourse experienced by the females which in some cases result in fear of sex makes the couple to loose interest in themselves. If medical assistance, often lacking in rural areas of Nigeria, to correct injury or wound is not given, with counseling to improve the relationship, the marriage can break up. The break up of a family may create social and psychological problems because the children will be adversely affected.

Also, sexual dysfunction presumably happens when women suffers painful sexual intercourse created by difficulty in penetration. Scar from mutilation reduces elasticity of the vagina opening. There is also reduction in sexual sensitivity thereby preventing the wife and the husband from performing and enjoying their conjugal rights.

Shock often accompany female genital mutilation. Sudden blood loss, severe pain and trauma all attended with fear leads to shock in victims. Death can be prevented only if blood transfusion and emergency resuscitation from medical experts, which are lacking in rural areas of Nigeria, are given. In addition, victims suffer traumatic pains. The labia minora and the clitoris are highly sensitive areas because of the dense concentration of nerve endings. Non- use of anesthesia, in a large case of FGM operations, result in traumatic pain for the victims.

Another serious effect of FGM is haemorrhage. Profuse bleeding from the wound, immediately after the operation or two to three days afterward do occur after mutilation. Excessive bleeding immediately when the clitoris is cut off occurs and this becomes difficult to control because of the sensitive nature of the area and also because of the presence of other sickness such as sickle cell and infections. Female genital mutilation often results in infections (Insel and Rath, 2006). Infection occur through mutilation performed under unhygienic conditions, using unsterilized instruments and application of substance such as herbs, or ashes to the wound and also by binding of the legs to prevent wound drainage, and due to lack of adequate follow - up medical treatment.

Furthermore, Keloid Scar formation may occur in victims of female genital mutilation. This can occur as a consequence of slow and incomplete healing as a result of post - operation infection. Keloid Scar often results to painful menstruation as well as cause sexual and psychological problems due to difficulty in penetration during intercourse.

\section{Constraints of female Genital Mutilation Eradication in Nigeria:-}

Inspite of the numerous deleterious consequences of female genital mutilation, and the fact that this archaic practice has no place in modern civilization, evidences have shown that it is popular in Nigeria, particularly in the rural areas where the population consist mainly of illiterates. The popularity of female genital mutilation in Nigeria is due to these factors among others.

1. Ignorance:- Ignorance is a product of illiteracy. Ignorance is one of the main factors promoting the practice of female genital mutilation among the rural population of Nigeria. As a result of lack of knowledge of the disastrous effects of FGM, the practice becomes difficult to eradicate.

2. Economic motives:- Traditional circumcisors are highly revered in places where the practice is popular and entrenched in their culture. Also these circumsicors derive substantial income from the practice. Therefore, they see the practice of FGM as their own means of making money and livelihood. So they do everything to promote this aspect of their culture, and resist its eradication.

3. Perceived Benefit for Reproductive Health:- Female genital mutilation is erroneously perceived as being beneficial for reproductive health, notably for its supposed prevention of complications in child birth and for its contribution to cleanliness in the genital area and avoidance of diseases.

4. Curbing Promiscuity:- Female genital mutilation is regarded as a means of curbing promiscuity, preserving Virginity, (particularly in the case of infibulations) and so avoiding disgrace to the girl's family, and enhancing marriage prospects.

5. Attitude of Federal Government:- The Federal Governments non-challant attitude to FGM eradication promotes and encourage the practice in Nigeria because only Cross River, Delta, Edo and Ogun States are the only states that had enacted law banning the practice since the Civilian rule in 1999, while the federal government is yet to outlaw it.

6. Male Prejudice:- Female genital mutilation is carried out in order to ensure male dominance and to give more pleasure to the husband during sexual intercourse by tightening the vagina (Hosken 1979). Other reasons given by Hosken (1979) are to prevent labia hypertrophy, to improve fertility; for religious rights and obligations.

7. Culture and tradition:- Majority of those who practice FGM regard it as a good custom and tradition which they inherited from past generations. Therefore it behoves on them not only to continue it, but to pass it on to the coming generation. So tradition is a formidable force to contend with in eradicating female genital mutilation in Nigeria. 


\section{Conclusion and Recommendations}

This paper discussed the historical development of female genital mutilation along with the types practiced in Nigeria. The various deleterious consequences of the practice were also examined, and it was found out that no single benefit was derivable from the practice and that the girl child and women were the victims. Even though FGM is archaic and outdated, the practice is still popular in Nigeria. As a result, this paper highlighted the factors that hampers its eradication from the Nigeria society.

Sequel to these factors, efforts to eliminate FGM should be backed up by strictly enforced legislative provisions by the Federal government, as well as the development of alternative sources of income for the traditional circumcisors. Government at all levels (Local government, State and federal) should create the awareness of the deleterious health consequences of FGM through mass media to target rural dwellers. Social agencies and agents, formal and non formal organizations should be so involved. In addition, school curriculum, at all levels of education, and should include such topics as female genital mutilation.

\section{References}

[1] Adeneye, A.K. (1995). Female circumcision in South West Nigeria

[2] A case study of Owu Abeokuta. Unpublished B.Sc. Thesis submitted to the Department o Sociology, Olabisi Onabanjo University, Ago - Iwoye.

[3] Akpabio, U.S. (1995). A study of the practice of Female circumcision in Akwa - Ibom State. A project submitted to the Inter African Committee (Nigeria), Lagos

[4] Alan, D. (1994). Infibulation in the Republic of Djibouti. Thesis No: 31, University of Bardeaus College of Medicine, Djibouti.

[5] Anderson, B.L. (2001). The long - term Reproductive Health consequences of FGM in rural Gambia. A community based survey. The tropical medicine on International Health. 6. (8).

[6] Anderson, B.L (1989), How to Eradicate circumcision of girls: A study of efforts in Egypt, Kenya and Mali

[7] Assaud, M (1990). Female circumcision in Egypt, A current research and social implications. American University of Cairo. Stu dies in Family Planning Vol. 2.

[8] Black, M. (1993). The Health and the Status of Women United Nations Children's Fund, New York, U.S.A

[9] Darer. A.A. (1993). Female circumcision and its consequences for mother and child. A paper presented to the African Symposium of the third world, Yaounde.

[10] Dorkenoo, E. (1994). Cutting the Rose. Female Genital mutilation. The practice and its prevention 379 Brixton, London, Minority Right Report.

[11] Efusi, D. and Bafrow, B. (1993). A proposal: women health promotion project with a focus on the prevention of genital mutilation a working model for the West African Region, background Research Work. London

[12] Ezumezu, B.U. (1993). Determining the magnitude of female circumcision in Oyi L.G.A of Anambra State and identifying the social and cultural factors that determine the practice. A research project submitted to inter - African.

[13] Gudeta T. (1994). The silent shame" private Decisions. Public Denatee Panos Publication, London.

[14] Hosken, P.F. (1993). The Hosken Report on Genital and Sexual Mutilation of Females, Fourth Revised Education, (WIN NEWS) $\left(92^{\text {nd }}\right.$ ed.). U.S.A. Women International Network (WIN)

[15] Insel, P.M and Roth, W.T (2006). Core concepts in Health, (10 ${ }^{\text {th }}$ ed.) Mc Graw Hill. New York.

[16] Owumi, B.E (1993). A social - cultural analysis of female circumcision among the Urhobo. A study of the Okpe people of Delta state. A project submitted to the Inter African Committee (IAC Nigeria) Lagos.

[17] Smabo, A. (1993). National Council of Women's society of Nigeria and the crusade on VVF, national Council of women's Societies of Nigeria, Lagos.

[18] Minority Right Group (1985), female Circumcision, Excision and Infibulations, 47, July.

[19] U.N.D.S. (1985). National Baseline survey on positive and Gharmful traditional practices Affecting women in Nigeria, centre for Gender and Social Policy studies OAU Ile-Ife, for Federal Ministry of women Affairs 